\title{
Impact of Scholar-Practitioners Gap on Research Output in Kenyan Hospitality Industry
}

\author{
Peter Muchai $^{1 *}$, Billy Wadongo ${ }^{2}$ and Tom Olielo ${ }^{2}$ \\ ${ }^{1}$ Department of Hospitality and Tourism management, Kenya Methodist University, Nairobi, Kenya \\ ${ }^{2}$ Department of Eco-Tourism, Hotel and Institution Management, Maseno University, Maseno,Kenya \\ * E-mail of the corresponding author: muchai2000@gmail.com
}

\begin{abstract}
The objectives of this study were to establish the extent to which scholars research are relevant to practitioners and to establish the strategies used by scholars to disseminate research findings for practitioners' consumption in Kenyan hospitality industry. The study used the mixed-method approach. The study used the convergent design, where both qualitative and quantitative data sets were collected and analysed simultaneously. A total of 389 respondents participated in this study, including 226 hospitality practitioners and 163 hospitality scholars in Kenya. The study found out that most research done by the hospitality scholars in Kenya are based on a hypothetical problem rather than pragmatic ones. Scholars use jargons, abbreviations, and statistical language in their research that are incomprehensible by practitioners, this reduces the usability of research ideas by the practitioners. The study also found out that practitioners are willing to participate in research activities when they are invited, given time and supported by their organisations.
\end{abstract}

Keywords: Scholar-practitioner gap, Research relevance, Research dissemination, Hospitality, Kenya

DOI: $10.7176 /$ JTHS/45-05

Publication date: December $31^{\text {st }} 2019$

\subsection{Introduction}

\subsection{Background information}

Scholars are usually interested in theoretical bias that advances their objective of original research and tenure. Practitioners, on the contrary, require readily available knowledge for practical solutions to achieving organisational effectiveness (Bolton \& Stolcis, 2003). Scholars and practitioners have different research interests. Scholar aims at identifying generalizable rules that lead to predictions rather than addressing pragmatic concerns on specific current problems. Industry practitioners claim that scholars' research often does not align with their needs. The emphasis on some publications is especially crucial for young faculty who, to achieve tenure must produce papers and get grants. Therefore, the burden to do research that is time-bound and easier to publish, push young faculty to do less relevant research. Another gap is experienced in the dissemination of research findings by the scholars to reach the targeted audience. Hospitality researches no matter how innovative may never reach the practitioners unless they disseminated appropriately and timely. Many scholars are not trained, rewarded or supported to disseminate research findings beyond scholar journals. The conventional model of knowledge transfer is linear; that is, the information usually flows from the information provider (scholar), via chosen media to the information user (practitioner). This model assumes that dissemination is one way, top-down flow of information from 'experts' to passive audience. In reality, information flow is a complex interactive process, multi-directional exchange of knowledge and ideas that should be embraced by scholars and practitioners for mutual benefit (Cotton, 2009; Roper, 2002; Wadongo, 2010; Saywell, 2010).

\subsection{Statement of the problem}

The antagonistic relationship between scholars and practitioners has affected the research outcomes. Academics and practitioners frequently have varied interests and viewpoints that influence their respective priorities. These priorities include services such as continuing education, professional recognition, organisational philosophy, networking opportunities, as well as access to hospitality research publications. Differences exist in ways in which hospitality scholars and practitioners approach finding solutions to problems because of training and conditioning variations across the two occupations. This has been associated with the view that, knowledge of theory and knowledge of practice as two distinct types of knowledge, which formulates different types of questions and require different solutions. Scholars and practitioners have varied research interests. Topics of interest to practitioners are hardly ever addressed in academic journals. Scholars in pursuit of tenure and promotion goals often fail to write for a practitioner audience, neglecting practice-oriented publications. Another challenge is associated with knowledge dissemination problem. Scholar research findings may not be translated into practice 
because of difficulties with practitioners understanding scholars jargon and complexity in interpreting statistical data.

\subsection{Research objectives}

To establish the extent to which scholars research are relevant to practitioners in Kenya hospitality industry Establish the strategies used by scholars to disseminate research findings for practitioners' consumption in Kenyan hospitality industry

\subsection{Literature review}

\subsection{Scholar-Practitioner perception differences}

Weick (1999) noted that theories that were "moving," were the theories that mattered to others emotionally and played a substantial role. He observed that individuals responded positively to an argument that affirms them than an argument that disaffirms them. In common consultant parlance, they are likely to react more positively to language that wins both their hearts and minds. Research on self-affirmation supports this argument. Other studies have confirmed that individuals seek and interpret information in ways that preserve a positive self-image (Alicke, et al., 1997). Thus, research that threatens a practitioner's self-image evokes negative emotions, but a study that is affirming evokes more positive emotions. In other words, even if scholar writing does not explicitly include an emotional appeal, it may evoke practitioner emotion based on how affirming it is.

Most of the studies by scholars may not have a significant impact, regardless of how relevant they are because of how they flow from the researcher to the article report. Research reports are usually presented in rather austere, decontextualized ways, even though the context out of which they have been developed is vibrant, they may not convey an appeal to pathos. Studies by scholars rarely affirm practitioners' opinion in any explicit way. An emotional connection with practitioners has to happen somewhere if researchers' contributions are to take hold in practice. If the relationship between researchers and practitioners' centres around "news briefs" on the websites or implications for practice proffered at the ends of the research report, the relationship will remain distant and onesided and will be less engaging (Alicke, et al., 1997).

\subsection{Scholar research dissemination strategies for practitioner consumption}

Piccoli and Wagner (2003) emphasised the importance of hospitality scholars to disseminate their research findings to help industrial practitioners solve operational challenges. The transfer of knowledge through various channels is usually viewed as an obstacle to ensuring that hospitality researches are accessible to practitioners. The problem is that hospitality practitioners are unaware of the findings of scholar research (Hollenbeck, et al., 2004). Knowledge transfer is complicated by the fact that scholars are motivated to publish in academicoriented journals versus practitioner-oriented periodicals (Bolton \& Stolcis, 2003; Raadschelders \& Lee, 2011). Unfortunately, topics of interest to practitioners are rarely addressed in academic journals (Szajna, 1994). Many practitioners may fail to read scholarly publications, primarily because they are coded with jargon and statistical methods that are not easily comprehend (Rynes et al., 2002). Academics in pursuit of tenure and promotion goals often fail to write for a practitioner audience, neglecting practice-oriented publications and reporting findings in esoteric terms (Rynes et al., 2002). Roper (2002) observed that academics have a style of discourse that is consensual and participatory, while practitioners are submissive to authority relationships where engagement is hierarchical.

Practitioners may fail to adopt the findings of research in the hospitality field because the knowledge that is produced by the scholars is not in a form that can be readily used in contexts of practice (Smart, 2003). Argyris and Scho"n (1996) argue that research knowledge will be useful only if scholars, consultants and practitioners collaborate in interpreting and implementing research findings. Researchers are blamed for paying little attention to transferring the knowledge they produce (Smart, 2003). Beer (2001) recommends that researchers take responsibility for specifying how the knowledge they generate should be implemented. Traditional knowledge transfer practices often inhibit the implementation of proposed solutions. Such practices include the use of authoritarian and coercive styles of imparting knowledge, defensiveness routines by researchers and selfinterested recommendations mostly by research consultants that maintain or increase clients' dependence on their services. Mohrman et al. (2001) empirically examined the perceived usefulness of research by practitioners in a context where researchers were not playing an action-oriented interventionist role. They found that practitioners in companies undergoing change viewed research results as useful when they were jointly interpreted with researchers and when practitioners had opportunities to self-design actions based on the research 
findings. He concluded that "perceived usefulness" requires far more than only researching relevant areas and methodology.

Additionally, researchers must do more than work collaboratively with industry practitioners to understand research findings. Many factors influence the consumption of research. Empirically, less is known about what motivates the research to happen or not happen. Golden-Biddle et al. (2002) questioned whether the knowledge remains the same in its movement from a researcher to a practitioner. The nature and use of recommendations change significantly as they are transmitted and adopted. Practitioners selectively interpret and use knowledge as it serves their purposes, fits their unique situations, and reflects their relations with the researcher. What makes research findings convincing and therefore, utilised is a rhetorical question (Van de Ven \& Schomaker, 2002). Rhetoric is the use of persuasion to influence the thought and conduct of the audience. The persuasiveness of the research findings are in the "eyes" of the practitioners, not just the researcher and therefore require understanding the context and assumptions of the audience. Davis (1986) argues that what influences practitioners to view research as impressive or classical is the degree to which the scholar challenges the practitioners' assumptions. Knowledge transfer is not only a function of the logic and data supporting findings but also the extent to which the researcher is viewed as a credible witness and ability to stir the emotions of the audience. Another problem of viewing the gap between scholars and practitioners as a knowledge transfer problem is the assumption that practitioners' knowledge is derived from scholar knowledge.

\subsection{Practitioners perception towards research outcome}

Scholars and practitioners have different research interests. Scholars often use research techniques that do not provide answers to questions of concern to practitioners (Deadrick, et al. 2009). Although both are concerned with causal inference, the scholar seeks to identify generalizable rules that lead to probabilistic predictions (Roper, 2002). This aim requires experimentation, employing sophisticated quantitative methodologies that most practitioners are uncomfortable or unaccustomed with. Although academic research is often open-ended and ongoing, practitioners, in contrast, often attempt to solve a specific problem, in a particular setting, within a limited time frame (Roper, 2002).

Typical scholars are accustomed to having an impact in scholarly writing through the strength of logic and data. They find gaps of some kind, convince others of their importance and then attempt to fill them in their work. Although this works for scholars, it is not all there to have an impact, and it is likely not to appeal to practitioners who are not interested in or aided by filling scholarly holes. Rather than addressing pragmatic concerns and offering solutions to current problems, scholars' research often does not align with practitioner needs. Even if academics address the topics of interest for practitioners, there is no surety that this new knowledge will be disseminated to those who need it most on time (Golden-Biddle \& Locke, 2006).

The emphasis on some publications is especially crucial for young faculty who, to achieve tenure must produce papers and get grants. Therefore, the pressure to do research that is tightly focused and relatively easier to publish can push young faculty to do less relevant research. This becomes a habit over the years leading to the tenure decision, and hence longstanding habits that are very hard to break. These same trend influences graduate students who may be interested in academic careers because there is increasing competition for academic posts in their field. Graduate students researches are frequently circumscribed so that the student can graduate at a time (Millar, et al., 2008).

While academic research may not be seen as relevant, it is usually rigorous. Academics deepen their understanding by applying thorough analysis and thought to decode underlying principles and to develop theories to explain their findings. This focus on rigour is a hallmark of the best academics. They know their research will be exposed to criticism by specialists from their discipline. While this may promote caution in the topics taken on, it has the virtue of incentivizing methodological soundness and critique (Millar, et al., 2008).

\subsection{Methodology}

\subsection{Research design}

The study used the convergent design where both qualitative and quantitative data sets were collected and analysed simultaneously and then merged into an overall interpretation. This design is used when a researcher wants to compare quantitative and qualitative information to present well-corroborated conclusions (Creswell, 1999). It is also used when a researcher wants qualitative data to validate the results from a quantitative survey. It is also 
an efficient design because both types of data are collected and analysed during the same phase of the study (Creswell et al., 2007).

\subsection{Sample Size}

The sample included hotel practitioners in four and five-star hotels, hospitality scholars in Kenyan universities and Key Industry Informants (KII). According to Hotels and Restaurants classification (2017) by Tourism Regulatory Authority (TRA), there were twenty-eight (28) hotels which were classified as four and five-star in Kenya. All participated in this study. Hospitality practitioners within the hotel included hotel managers, accommodation/housekeeping managers, food and beverage managers, executive chefs and front office managers. Section managers of hotel support departments such as Finance, Human Resource, Maintenance, Security, ICT etc. did not participate in this study. Hospitality scholars included university teaching staff in Kenya. There were twenty-seven (27) universities and university colleges in Kenya offering hospitality and related programmes. Key industry informants (KII) included representatives from Tourism Regulatory Authority (TRA), Kenya Association of Hotelkeepers and Caterers (KAHC), Commission for University Education (CUE) and Kenya Utalii College (KUC).

\subsection{Sampling Techniques}

Using Kenya gazetted hotel classification of 2016 a list of 4 and 5-star was obtained. Hotel classification in Kenya is a rigorous exercise conducted by Tourism Regulatory Authority (TRA) established under the Kenya Tourism Act No.28 of 2011. The authority periodically undertakes national classification of all hotels establishment intending to ensure high hotel standards and quality of services. Five (5) star and four (4) star hotels were found to be ten (10) and eighteen (18), respectively. All twenty-eight(28) 4 and 5-star hotels in Kenya participated in this study.

\subsection{Research Instruments}

Three data collection methods were used to complement each other to increase the credibility and validity of the findings. Use of more than two data collection method is referred to as triangulation. Triangulation allows crossexamination of the findings to explain fully the richness and complexity of the phenomenon under study. The study used questionnaires, interviews and FGD methods of data collection. Questionnaires are used to collect both quantitative and qualitative data while interviews and FGDs were used to collect qualitative data (Cohen et al, 2011).

\subsection{Reliability and validity of research instruments}

Pre-testing was done to improve the validity and reliability of the data collection instruments. A convenience sample of four (4) hotels and two (3) hospitality training institutions were used for pre-testing. The pre-testing sample was not included in the final study. Spearman-Brown Proficiency Formula (r Split- Half) was also used on the questionnaire. Split-Half (r) for the questionnaire was 0.87 . Split-Half estimate between 0.8 and 1.0 is accepted as reliable enough (Gay, 1992).

\subsection{Findings and discussion}

3.1 Response rate

A total of 389 respondents participated in this study. Hospitality practitioners were 226 (58\%) while scholars were $163(42 \%)$. In terms of years worked in the industry, the majority $(n=135,35.8 \%)$ of the respondents had $6-10$ years of experience with $63.2 \%$ of both scholars and practitioners having between 1 and 10 years of experience. This was an indication that most of the hospitality workers are relatively green in their careers.

In terms of education among the hospitality practitioners, the degree holders were the majority of the respondents at $87(44 \%)$, diploma $79(40 \%)$, certificate $14(7 \%)$, masters' holders were $13(7 \%)$ and doctorate $7(4 \%)$. However, among scholars the majority of the respondents were master holders at $81(49.4 \%)$, PhD holders were $56(34.1 \%)$, degree holders were $21(12.8 \%)$ with the only diploma and certificate holders being $6(3.6 \%)$. Among the hospitality scholars, the level of education holders increased with increase in level with $83.5 \%(n=137)$ of the respondents having either masters or doctorate level of education as compared to practitioners who comprised only $11 \%(n=20)$ of the respondents who had masters or doctorate (See table below). 
Table 3.1 Demographic characteristics of the respondents

Gender

Male

Female

Total

Experience (Years)

$1-5$

6-10

11-15

16-20

Over 21

Total

\begin{tabular}{cr}
$\begin{array}{c}\text { Both Scholars \& } \\
\text { Practitioners }\end{array}$ & Scholars \\
\hline
\end{tabular}

\begin{tabular}{cccccc}
\multicolumn{2}{c}{ Practitioners } & \multicolumn{2}{c}{ Scholars } & \multicolumn{2}{c}{ Practitioners } \\
\hline Frequency & $\%$ & Frequency & $\%$ & Frequency & $\%$ \\
\hline 198 & $55 \%$ & 76 & $46.6 \%$ & 122 & $61.9 \%$ \\
162 & $45 \%$ & 87 & $53.4 \%$ & 75 & $38.1 \%$ \\
$\mathbf{3 6 0}$ & $\mathbf{1 0 0 . 0 \%}$ & $\mathbf{1 6 3}$ & $\mathbf{1 0 0 . 0 \%}$ & $\mathbf{1 9 7}$ & $\mathbf{1 0 0 . 0 \%}$ \\
& & & & & \\
97 & $26.6 \%$ & 46 & $28.9 \%$ & 51 & $25.0 \%$ \\
137 & $37.5 \%$ & 50 & $31.4 \%$ & 85 & $41.7 \%$ \\
36 & $9.9 \%$ & 13 & $8.2 \%$ & 23 & $11.3 \%$ \\
30 & $8.2 \%$ & 6 & $3.8 \%$ & 24 & $11.8 \%$ \\
65 & $17.8 \%$ & 44 & $27.7 \%$ & 21 & $10.3 \%$ \\
$\mathbf{3 6 5}$ & $\mathbf{1 0 0 . 0} \%$ & $\mathbf{1 5 9}$ & $\mathbf{1 0 0 . 0} \%$ & $\mathbf{2 0 4}$ & $\mathbf{1 0 0 . 0} \%$
\end{tabular}

Marital status

\begin{tabular}{lcccccc} 
Single & 88 & $24.9 \%$ & 38 & $23.9 \%$ & 50 & $25.6 \%$ \\
Married & 263 & $74.3 \%$ & 118 & $74.2 \%$ & 145 & $74.4 \%$ \\
Others & 3 & $0.8 \%$ & 3 & $1.9 \%$ & 0 & $0 \%$ \\
$\quad$ Total & $\mathbf{3 5 4}$ & $\mathbf{1 0 0 . 0 \%}$ & $\mathbf{1 5 9}$ & $\mathbf{1 0 0 . 0 \%}$ & $\mathbf{1 9 5}$ & $\mathbf{1 0 0 . 0 \%}$ \\
$\begin{array}{l}\text { of Education } \\
\text { Certificate }\end{array}$ & 19 & $5.2 \%$ & 5 & $3.0 \%$ & 14 & $7 \%$ \\
Diploma & 80 & $22.0 \%$ & 1 & $0.6 \%$ & 79 & $40 \%$ \\
Degree & 108 & $29.7 \%$ & 21 & $12.8 \%$ & 87 & $44 \%$ \\
Masters & 94 & $25.8 \%$ & 81 & $49.4 \%$ & 13 & $7 \%$ \\
Doctorate & 63 & $17.3 \%$ & 56 & $34.1 \%$ & 7 & $4 \%$ \\
Total & $\mathbf{3 6 4}$ & $\mathbf{1 0 0 . 0} \%$ & $\mathbf{1 6 4}$ & $\mathbf{1 0 0 \%}$ & $\mathbf{2 0 0}$ & $\mathbf{1 0 0 \%}$ \\
\hline
\end{tabular}

3.2 Relevance of hospitality research in Kenya

Both scholars and practitioners agreed $(n=109,30 \%)$ and strongly agree $(n=227,63 \%)$ that reading research frequently improves knowledge and skills. Both practitioners $(\mathrm{n}=176,85 \%)$ and scholars $(\mathrm{n}=133,86 \%)$ agreed and strongly agreed that the research done by hospitality scholars in Kenya are relevant and significant $\left(\chi^{2}=40.278, \mathrm{df}=4\right.$, Sig. $\left.=0.001\right)$. Only 1 scholar and 12 practitioners opposed by strongly disagreeing the relevance of the study conducted by hospitality scholars. This finding indicates that scholars and practitioners have faith in the research work done by hospitality scholars in Kenya. Majority of hospitality scholars ( $\mathrm{n}=87,57 \%)$ disagreed and strongly disagreed that they consult practitioners on topics they research on, and only $77(37 \%)$ of practitioners agreed and strongly agreed that they have ever been consulted by scholars on the problems they would like researched. This finding confirms the study by Sutton (2004) that most research done by the scholars are based on the hypothetical problem rather than pragmatic ones. There was a weak negative correlation $(\mathrm{R}=-$ 0.100 ) between the opinion on research relevance and years of experience of the respondents (see table 3.2). 


\begin{tabular}{|c|c|c|c|c|c|c|c|c|}
\hline & \multicolumn{3}{|c|}{ Mean } & \multirow[b]{2}{*}{ 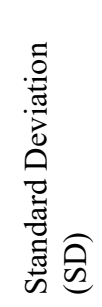 } & \multirow[b]{2}{*}{ 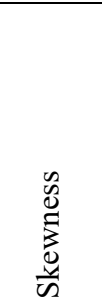 } & \multirow[b]{2}{*}{$\begin{array}{l}\frac{n}{0} \\
0 \\
0 \\
0 \\
0\end{array}$} & \multirow[b]{2}{*}{ 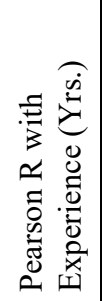 } & \multirow[b]{2}{*}{ 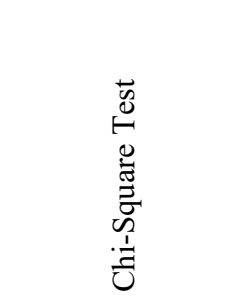 } \\
\hline & 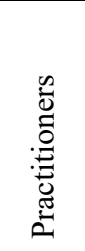 & 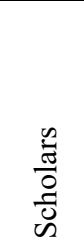 & 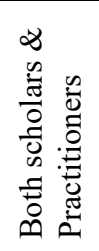 & & & & & \\
\hline $\begin{array}{llll}\text { Reading researches } & \text { frequently } & \text { improves } \\
\text { knowledge and skills } & & \\
\end{array}$ & 4.47 & 4.60 & 4.53 & 0.743 & $1.901^{-}$ & 4.002 & $\begin{array}{c}- \\
0.113 \\
\end{array}$ & $\begin{array}{c}\chi^{2}=63.128, \mathrm{df}=4 \\
\text { Sig. }<0.005\end{array}$ \\
\hline $\begin{array}{l}\text { Topics researched by Scholars are highly } \\
\text { relevant to the practitioners }\end{array}$ & 4.20 & 4.31 & 4.25 & 0.782 & 0.924 & 0.551 & 0.100 & $\begin{array}{c}\chi^{2}=40.278, \mathrm{df}=4 \\
\text { Sig. }=0.001\end{array}$ \\
\hline $\begin{array}{l}\text { Scholars frequently consult practitioners on } \\
\text { research topics they would like researched }\end{array}$ & 3.33 & 2.64 & 3.03 & 1.279 & 0.227 & $1.234^{-}$ & $\begin{array}{c}- \\
0.093\end{array}$ & $\begin{array}{l}\chi^{2}=14.265, \mathrm{df}=4 \\
\text { Sig. }=0.579\end{array}$ \\
\hline $\begin{array}{l}\text { Scholars disseminate research findings in a } \\
\text { manner that is easily consumed by practitioners }\end{array}$ & 3.45 & 2.73 & 3.14 & 1.234 & 0.101 & $\begin{array}{r}- \\
1.073\end{array}$ & $\begin{array}{c}- \\
0.211 \\
\end{array}$ & $\begin{array}{c}\chi^{2}=48.027, \mathrm{df}=4 \\
\text { Sig. }=0.001\end{array}$ \\
\hline $\begin{array}{l}\text { Practitioners are always invited to research } \\
\text { conference by local universities }\end{array}$ & 3.05 & 2.94 & 3.00 & 1.268 & 0.303 & 1.134 & $\begin{array}{c}- \\
0.169\end{array}$ & $\begin{array}{c}\chi^{2}=36.592, \mathrm{df}=4 \\
\text { Sig. }=0.02\end{array}$ \\
\hline
\end{tabular}

$\mathrm{N}=377$

NB: Note: $5=$ Strongly Agree, 4=Agree, $3=$ Undecided, 2= Disagree, $1=$ Strongly Disagree

$\chi^{2}$ association at $95 \%$ and confidence interval $=0.05$

\subsection{Research dissemination strategies}

Half of the practitioners $(n=101,50 \%)$ disagreed and strongly disagreed that scholars disseminate the research findings in a manner that is easily consumed by the practitioners. It was also noted that $50(25 \%)$ of the practitioners were undecided on this matter. Only 56 (36\%) of the scholars agreed and strongly agreed that they disseminate research findings in a friendly manner for practitioners' consumption. This indicates that scholars are quite aware of their dissemination role but have not executed it well. Most scholars disseminate research information in academic journals, libraries, magazines, newspapers articles and through conferences and symposiums. Both scholars $(n=137,92 \%)$ and practitioners $(n=111,56 \%)$ believed that hospitality practitioners in Kenya do not search for research information on their own. Practitioners identified lack of organisational motivation and incentives as another reason for not having an interest in research activities. On statistical analysis used by scholars in their research, practitioners $(n=145,71 \%)$ had the view that they are not easily understood which is more the same with the scholars $(n=99,66 \%)$. This is in tandem with Sutton (2004) finding that scholars use jargons, abbreviations and statistical language that is well understood by fellow over-trained scholars and incomprehensible by practitioners. This reduces the likelihood of the research ideas ever be used by the practitioners. For this reason, scholars were recommended to present the research in a more palatable state for more natural consumption by the layman consumers. There was a weak negative correlation $(\mathrm{R}=-0.211)$ between the perception on research dissemination strategies and years of experience of the respondents, which was significant at chi-square $\chi^{2}=48.027, \mathrm{df}=4$, Sig. $=0.001$ (See table 3.2).

\subsection{Practitioners participation in the research conference}

Fewer practitioners $(n=78,38 \%)$ agreed and strongly agreed that they have ever been invited to a research conference in Kenyan university. A significant number of practitioners ( $n=47,31 \%)$ and scholars $(n=39,26 \%)$ were undecided on this matter. This finding shows that the effort of engaging and involving practitioners in research conference where research findings, innovations and inventions are discussed have not adequately incorporated practitioners. Practitioners attribute their low research participation to lack of time. Scholars $(\mathrm{n}=138$, $90 \%)$ attribute low practitioners' participation to lack of interest as opposed to practitioners $(\mathrm{n}=96,48 \%)$ who believed the same. Other reasons that hinder practitioners from attending research conferences include unpredictable workload, cost implications-especially when travel and accommodation expenses are involved, the perception that their contribution is not valued and complex bureaucratic requirement.

To address these challenges, Mitchel et al. (2002) suggested that conference organiser should simplify procedures, organise the conference in a way that is efficient but flexible, have clear objectives and process, and involve 
practitioners in research conference planning. This finding means that practitioners are willing to participate in research activities if they are invited, given time and supported by their organisations. However, they are likely not searching for studies done by scholars on their own. This calls for scholars to engage, invite and share their findings beyond journal publications. Scholars and practitioners in Kenya are therefore encouraged to create forums where research findings will be highly shared for the benefit of the practitioners. There was a weak negative correlation $(\mathrm{R}=-0.169)$ between the opinion on practitioners participation in research conference and years of experience of the respondents, which was significant at chi-square $\chi^{2}=36.592, \mathrm{df}=4$, Sig. $=0.02$ (See table 3.2).

\subsection{Conclusion and recommendation}

The conflicting relationship between scholars and practitioners has affected the research outcomes. Practitioners confirmed that they are not consulted by the scholars on the areas they would want to be researched on. This is because the scholars are motivated by the number of publications within the time constrains. This has led to the production of researches that address hypothetical problems rather than real practice challenges. Scholars have not adequately disseminated the research finding in a manner that is easily accessed and comprehended by the practitioners. Majority of scholars are quite aware of the challenge. Scholars are urged to disseminate their research in a friendly by avoiding jargons, complex statistical statements and present the findings in forums where practitioners likely participate. Practitioners on their own are not likely to look for research information. Most hospitality practitioners are not able to attend research conferences due to lack of time, cost implications, bureaucratic procedures and the feel of not adding value to the conference especially if not invited. The finding showed that practitioners are willing to participate in research activities if they are invited, given time, if supported by their organisations and if involved in the planning of the conference.

\section{References}

Alicke, M., LoSciavo, F. Zerbst \& Zhang, S., (1997). The person who outperforms me is a genius: Maintaining perceived competence in upward social comparison. Journal of Personality and Social Psychology, 17: 19-23.

Argyris, C., \& Scho“n, D. (1996). Organization learning II: Theory, method and practice. Reading, MA: AddisonWesley.

Beer, M. (2001). Why management research findings are un-implementable: An action science perspective. Reflections; 2(3): 58-65

Bolton, M., \& Stolcis, G., (2003). Ties that do not bind: Missing on the specious relevance of academician research. Public Administration Review, 22:87-94.

Bolton, M., \& Stolcis, G., (2003). Ties that do not bind: Missing on the specious relevance of academician research. Public Administration Review, 22:87-94.

Cohen, L., Manion, L. \& Morrison, K. (2011). Research Methods in Education. (7 Ed.). New York: Routledge. (705 siders). Støttelitteratur: Kleven, T. A. (Red.)

Creswell, J. (2008). Research design: Qualitative, quantitative, and mixed methods approach (3rd Ed.). Thousand Oaks, CA: Sage Publications.

Creswell, J. W., \& Plano Clark, V. L. (2007). Designing and conducting mixed methods research. Thousand Oaks, CA: Sage.

Davies, P. (2004). Is Evidence-Based Government Possible? Paper presented at the $4^{\text {th }}$ Campbell Collaboration Colloquium. Washington DC.

Deadrick, D., \& Gibson, P., (2009). Revising the research-practice gap in HR: A longitudinal analysis. Human Resource Management Review, 12: 28-36.

Golden-Biddle, K., Locke, K., \& Reay, T. (2002) Re-conceptualizing knowledge transfer: Toward a theory of knowledge movement as a communicative process. Working paper; University of Alberta, Canada.

Hollenbeck, J., DeRue, D., \& Guzzo, R. (2004). Bridging the gap between I/O research and HR practice: Improving team composition, team training, and team task design. Human Resource Management

Kenya Association of Hotel Keepers and Caterers (2016). Members "Directory 2016”, Nairobi Chapter, Nairobi, Kenya

Kothari. C., (2007). Research Methodology: Methods and Techniques, $2^{\text {nd }}$ Ed. New Age International Publishers, New Delhi

Millar, M., Mao, Z. and Moreo, P., (2008)."Hospitality Management Scholars vs. the Industry: A Competency Assessment". Hospitality Management Paper 
Mitchell, G., Jong, I., Del Mar, C., Clavarino, A., Kennedy, R., (2002). General practitioner attitudes to case conference: How can we increase participation and effectiveness? The Medical Journal of Australia. 177. 95-7. 10.5694/j.1326-5377.2002. tb04680. x.

Mohrman, S., Gibson, C., \& Mohrman, A. (2001). Doing research that is useful to practice: A model and empirical exploration. Academy of Management Journal, 44: 357-375.

Piccoli, G. and Wagner, E. (2003). The Value of Academic Research. Cornell Hotel and Restaurant Administration Quarterly.

Raadschelders, J., \& Lee, K. (2011). Trends in the study of public administration: Empirical and qualitative observations from Public Administration Review, 2000-2009. Public Administration Review, 14: $189-205$.

Roper, L. (2002). Achieving successful academic-practitioner research collaborations. Development in Practice

Rynes, S., Brown, K., \& Colbert, A. (2002). Seven common misconceptions about human resource practices: Research findings versus practitioner beliefs. Academy of Management Executive, 4:3-51.

Sutton, R. (2004), "Prospecting for valuable evidence: why scholarly research can be a goldmine for managers", Strategy \& Leadership, Vol. 32 No. 1, pp. 27-33

Szajna, B. (1994). How much is information systems research addressing key practitioner concerns? DataBase

Van de Ven, A. \& Poole, M. (2002). Field research methods. In J. A. C. Baum (Ed.). Companion to organizations. New York: Oxford University Press.

Van de Ven, A., \& Johnson, P. (2006). Knowledge of theory and practice. Academy of Management Review, 19(5):367-371.

Van Scotter, J. and Culligan, P. (2003). The Value of Theoretical Research and Applied Research for the Hospitality Industry. Cornell Hotel and Restaurant Administration Quarterly. April

Van Scotter, J. and Culligan, P. (2003). The Value of Theoretical Research and Applied Research for the Hospitality Industry. Cornell Hotel and Restaurant Administration Quarterly. April

Wadongo, B., Kambona, O., Odhuno, E. (2011). Emerging critical generic managerial competencies: A challenge to hospitality scholars in Kenya. African Journal of Economic and Management Studies, 2(1):56-71.

Weick, K. (2005). The pragmatics of "really mattering" on policy issues: William Ouchi as an exemplar. Academy of Management Journal, 60:45-52. 